\title{
Relief and decay of flow stripes on Byrd Glacier, Antarctica
}

\author{
G. CASASSA \\ Byrd Polar Research Center and Department of Geological Sciences, The Ohio State University, Columbus, OH 43210, USA \\ H. H. BRECHER \\ Byrd Polar Research Center, The Ohio State University, Columbus, OH 43210, USA
}

\begin{abstract}
Curvilinear flow stripes appear on aerial photographs and satellite imagery of polar ice. On Byrd Glacier, Antarctica, flow stripes are especially prominent and can be detected on AVHRR imagery down to the ice shelf margin.

Aerial photographs of Byrd Glacier (Brecher, 1986) are used to determine photogrammetrically the relief associated with flow stripes on two transverse profiles separated by a distance of $65 \mathrm{~km}$. Two kinds of stripes are found, topographic and textural flow stripes. Topographic flow stripes are associated with a ridge-trough topography with double amplitudes of $7 \mathrm{~m}$ to $45 \mathrm{~m}$ and slopes of $1-7 \%$. The valleys of the topographic flow stripes appear bright in the photographs and correspond to snow-covered areas, while ridges appear in general as dark stripes that correspond to bare ice areas with abundant crevasses. Textural flow stripes correspond to bands of distinct crevasse pattern which are not associated with topography.

The photogrammetric information is correlated with the brightness pattern across flow stripes that appears on Advanced Very High Resolution Radiometer (AVHRR) data. Flow stripes decay rapidly on the AVHRR imagery over the first $40 \mathrm{~km}$ downstream from Byrd Glacier and some persist for nearly $400 \mathrm{~km}$ to the front of the Ross Ice Shelf.

Velocity was measured across a transect on the upstream photogrammetric profile. There are no velocity discontinuities across the boundaries of flow stripes, which shows that lateral shear between flow stripes is not a valid mechanism for explaining their persistence.
\end{abstract}

\section{INTRODUGTION}

Flow stripes are curvilinear features that appear on satellite imagery of polar ice for distances of up to several hundred $\mathrm{km}$ and can provide important information of present and past flow conditions. Flow stripes have been traditionally interpreted as flow lines (Crabtree and Doake, 1980). Casassa and others (1991) point out that this is not the case for an area west of Crary Ice Rise, where it was concluded that strongly curved flow stripes correspond to relict features.

Flow stripes appear on the imagery as bands of contrasting brightness. Dowdeswell and McIntyre (1987) described "bands of both heavily and less heavily crevassed ice and apparent flow lines and undulations" on Landsat MSS imagery of Byrd Glacier, Antarctica. Dowdeswell and McIntyre found good agreement between flow stripes on the Landsat image and topographic ridges derived from aircraft altimetry data.

Here we use several stereomodels from the first of two photogrammetric block triangulations of Byrd Glacier (Brecher, 1986) to measure two detailed surface elevation profiles across the glacier and to characterize the surface relief of flow stripes. In addition, ice velocities are computed for a reduced section of the upstream profile from the two sets of aerial photographs obtained eight weeks apart to search for any velocity discontinuities associated with the flow stripes. The photogrammetric profiles are then compared with near infrared AVHRR data of flow stripes flowing out from Byrd Glacier. The decay of the flow stripes is inferred from the AVHRR brightness signature of the stripes as they are traced down to the ice-shelf front.

\section{PHOTOGRAMMETRY}

\section{Surface elevation profiles}

\section{Method}

Surface elevation profiles across the whole width of the glacier were measured in two places. The upstream profile is located in a region where flow stripes are particularly prominent and the downstream profile is as far toward the Ross Ice Shelf as the available photography allows. Both profiles are shown on a Landsat MSS image on Figure 1. On this Landsat image, flow stripes appear to originate in an area $50 \mathrm{~km}$ to $120 \mathrm{~km}$ upstream 


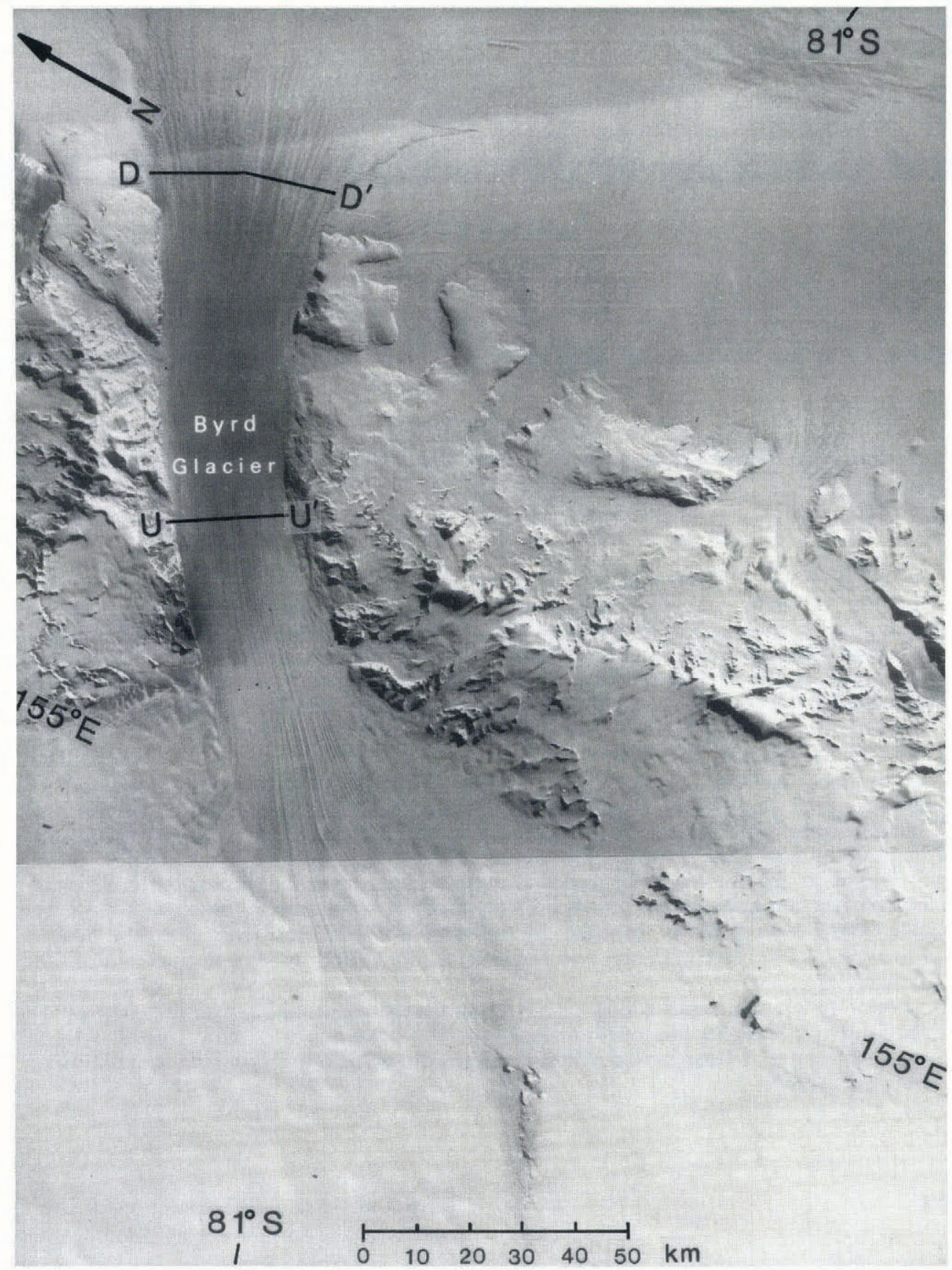

Fig. 1. Landsat-MSS image of Byrd Glacier, from figure 25 of Swithinbank (1988). The locations of the upstream $\left(U U^{\prime}\right)$ and downstream $\left(D D^{\prime}\right)$ photogrammetric profiles are shown.

of the upstream profile, where no aerial photography is available. Points in the profiles were chosen to represent what was judged to be the "'general ice surface", that is, measurements on prominent crevasses or on seracs or narrow ridges were avoided. The upstream elevation profile is $22.7 \mathrm{~km}$ long and consists of about 200 points with an average spacing of $110 \mathrm{~m}$. The downstream profile is $35.4 \mathrm{~km}$ long with about 220 points $160 \mathrm{~m}$ apart on the average.

The measurements were made on an analytical stereo plotter (Wild BC 1) on selected stereoscopic models from photographs taken 56 days apart, 6 December 1978 and 31 January 1979. The photographs have been used for a detailed study of surface motion of Byrd Glacier (Brecher, 1986) and were taken with a standard wide angle mapping camera (Wild RC 8) at an average scale of approximately $1: 49000$. Control points for setting up the stereo models came from the aerial triangulations of the two blocks of photographs for the previous surface motion study. Ten to 15 such points appear in each model and, with a few exceptions, all were used in each orientation, resulting in much larger than usual redundancy. Excellent results were obtained in absolute orientations, typically $7 \mu \mathrm{m}$ in photo $y$-parallaxes. RMS residuals on the ground are $0.6 \mathrm{~m}$ to $0.8 \mathrm{~m}$ in plan and $1.1 \mathrm{~m}$ in elevation.

Four models, one each from adjacent flight lines, were used to span the glacier for each elevation profile. There was considerable side overlap between models in each case and parts of the profiles are therefore duplicated in adjacent stereo models. A line was drawn on one of the diapositives for each model to mark the location of the 
profiles, and points reasonably evenly spaced along this line were then measured independently in each model. That is, no attempt was made to measure identical points in the overlapping regions, but nevertheless the overlapping elevation profiles are virtually identical. In two cases, although elevation differences also agreed very well, there were small systematic elevation offsets between models which could not be satisfactorily accounted for. Four of the six overlaps are between $3 \mathrm{~km}$ and $6 \mathrm{~km}$ long and contain at least 30 points each. The very good agreement of the independently measured profiles in these places suggests that the surface has been represented accurately. Using a conservative estimate of $10 \mu \mathrm{m}$ for precision of measurements on the photographs yields precision of $0.5 \mathrm{~m}$ for positions and $1.1 \mathrm{~m}$ for elevations in the terrain. Precision of elevation differences along the profiles is thus $1.1 \sqrt{ } 2=1.6 \mathrm{~m}$.

\section{Results}

Uncontrolled mosaics of the upstream and downstream profiles are shown in Figs. $2 \mathrm{a}$ and $3 \mathrm{a}$ respectively. Corresponding elevation profiles are shown in Figs. $2 b$ and $3 \mathrm{~b}$. Flow stripes appear on the photographs as bands of different crevasse texture and brightness pattern. From Figure $2 \mathrm{a}$ the general crevasse orientation of the upstream profile corresponds to that of splaying crevasses formed by lateral shear and longitudinal extension. However, the detailed structure of crevasses within flow stripes is largely
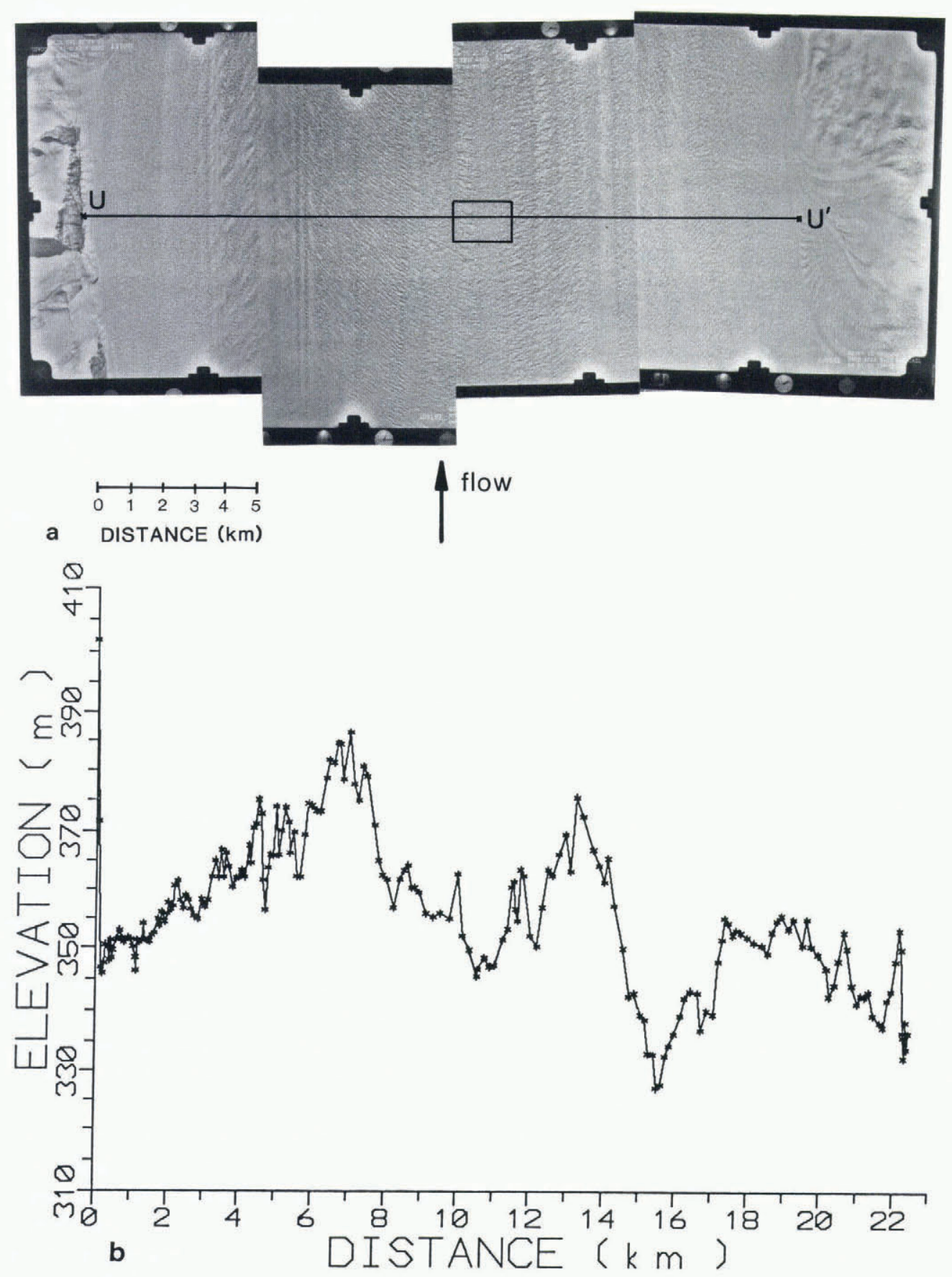

Fig. 2. a. Uncontrolled mosaic of aerial photographs showing the upstream profile of Byrd Glacier. The rectangle in the middle of the profile corresponds to Figure 4, where velocity measurements were carried out. $b$. Surface elevation of the upstream profile. 

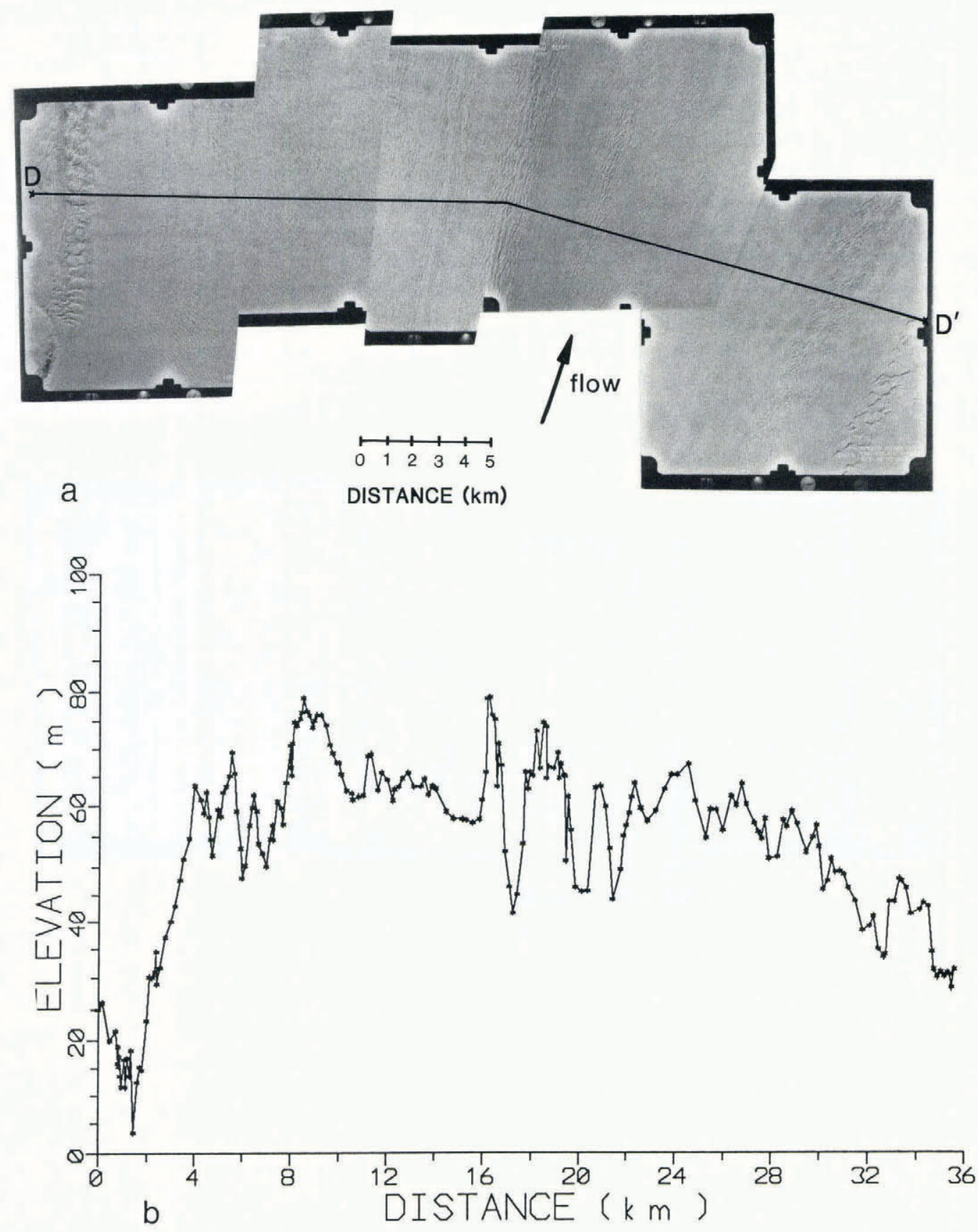

Fig. 3. a. Uncontrolled mosaic of the downstream profile. b. Surface elevation of the downstream profile.

chaotic, which is probably a result of the complex stress history. Stereoscopic inspection shows that bright stripes in the photographs appear snow-covered and are generally associated with valleys, while dark stripes appear as bare ice areas that usually correspond to ridges.

The upstream region has a large crevasse density and in general consists of bare ice. Net ablation occurs in this area probably associated with strong katabatic winds (Bromwich, 1992). Flow stripes here appear as bands each with a distinct crevasse pattern. Each stripe ranges from $0.1 \mathrm{~km}$ to $2 \mathrm{~km}$ in width. In the upstream profile there is a long-wavelength component $(5 \mathrm{~km})$ of surface elevation with ridge-valley double amplitudes up to $45 \mathrm{~m}$. Superimposed on the long-wavelength trend is a shortwavelength variation with wavelengths of $250 \mathrm{~m}$ to $1 \mathrm{~km}$, double amplitudes of about $10 \mathrm{~m}$ and slopes of $2-7 \%$. Narrow stripes are steeper than wide stripes. It is these short-wavelength variations that correspond in many cases with flow stripes. There are, however, several flow stripes in the upstream profile that do not correlate with any surface elevation change. This observation contrasts with the traditional view that flow stripes correspond to "gently undulating ridges and troughs" (Crabtree and Doake, 1980).

In the downstream profile flow stripes appear as bands of smooth ice adjacent to bands of crevassed ice each of which are $1 \mathrm{~km}$ to $2 \mathrm{~km}$ wide. Crevasses are much less prominent than in the upstream profile and are largely filled with snow. This filling may be because lateral shear is much smaller (Brecher, 1986) and crevasses are not opening as quickly, or because net accumulation occurs. There is a better correlation between flow stripes and elevation than at the upstream profile, and the slopes associated with stripes range from $1-7 \%$. The short 
wavelength component of the elevation profile is reduced compared to the upstream profile. The predominating wavelength $(\lambda)$ is $1.5-4 \mathrm{~km}$, with a double amplitude of $20-40 \mathrm{~m}$.

\section{Velocity profile}

The origin and persistence of flow stripes is unclear. An hypothesis is that flow stripes are formed where two ice tributaries converge and would therefore be associated with shear margins (Casassa and others, 1991). Large lateral shear occurs in shear margins, which could account for the crevasses observed in flow stripes. Crevassing would result in bands of less dense ice, which would be topographically higher once isostasy at depth is achieved. However, positive relief elements tend to collapse. Perhaps flow stripes are continually created, which means that lateral shear might occur everywhere that such stripes are observed.

In order to test this suggestion, a velocity transect was measured across some especially prominent flow stripes on the upstream profile. Forty measurements of displacements were carried out in the area shown with a rectangle in Figure 2a. This area is shown enlarged in Figure 4. Measurements are spaced an average of $47 \mathrm{~m}$ apart over a total distance of $1.8 \mathrm{~km}$. A stereo pair from each photo epoch is used. The photographs were taken 56 days apart. The selected site for closely-spaced determinations of velocity is at the center of the glacier. This is a region where lateral shearing is expected to be small. Yet flow stripes with strong topographic relief are prominent.

Errors of displacements are combinations of the errors across-flow coordinate. The velocity measurements are spaced about $47 \mathrm{~m}$, and so the standard error in strain
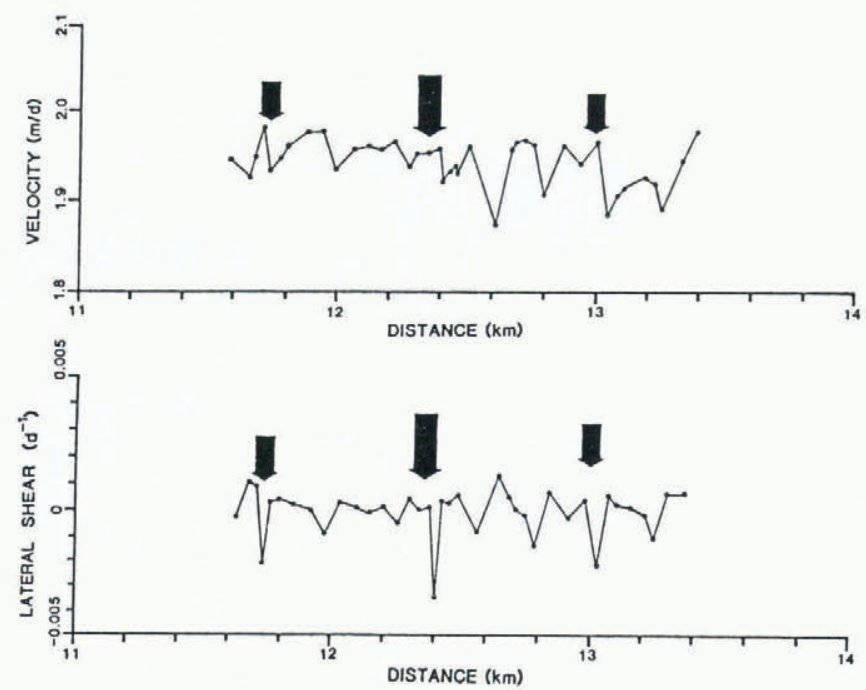

Fig. 5. Longitudinal component of velocity and lateral shear along the profile of Figure 4. The origin of the distance is the same as the one used for Figure $2 b$, that is, the left margin of the glacier. Vertical arrows show the position of flow stripe boundaries from Figures $2 a$ and 4 .

rate is typically $0.001 \mathrm{~d}^{-1}$, but can be as large as $0.006 \mathrm{~d}^{-1}$ for shear computed over closely-spaced measurements.

The speed and lateral shear are shown in Figure 5. The average speed of the points in the profile is $1.94 \mathrm{~m} \mathrm{~d}^{-1}$. Fluctuations up to $0.1 \mathrm{~m} \mathrm{~d}^{-1}$ about the mean speed are observed across the profile, but no significant in each position measurement and the error in the positions of the two stereomodels with respect to each other. The second error is estimated to be $3 \mathrm{~m}$ (Brecher, 1986), but it is systematic and does not affect velocity differences. The probable uncertainty of relative velocities

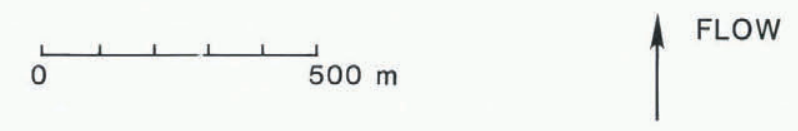

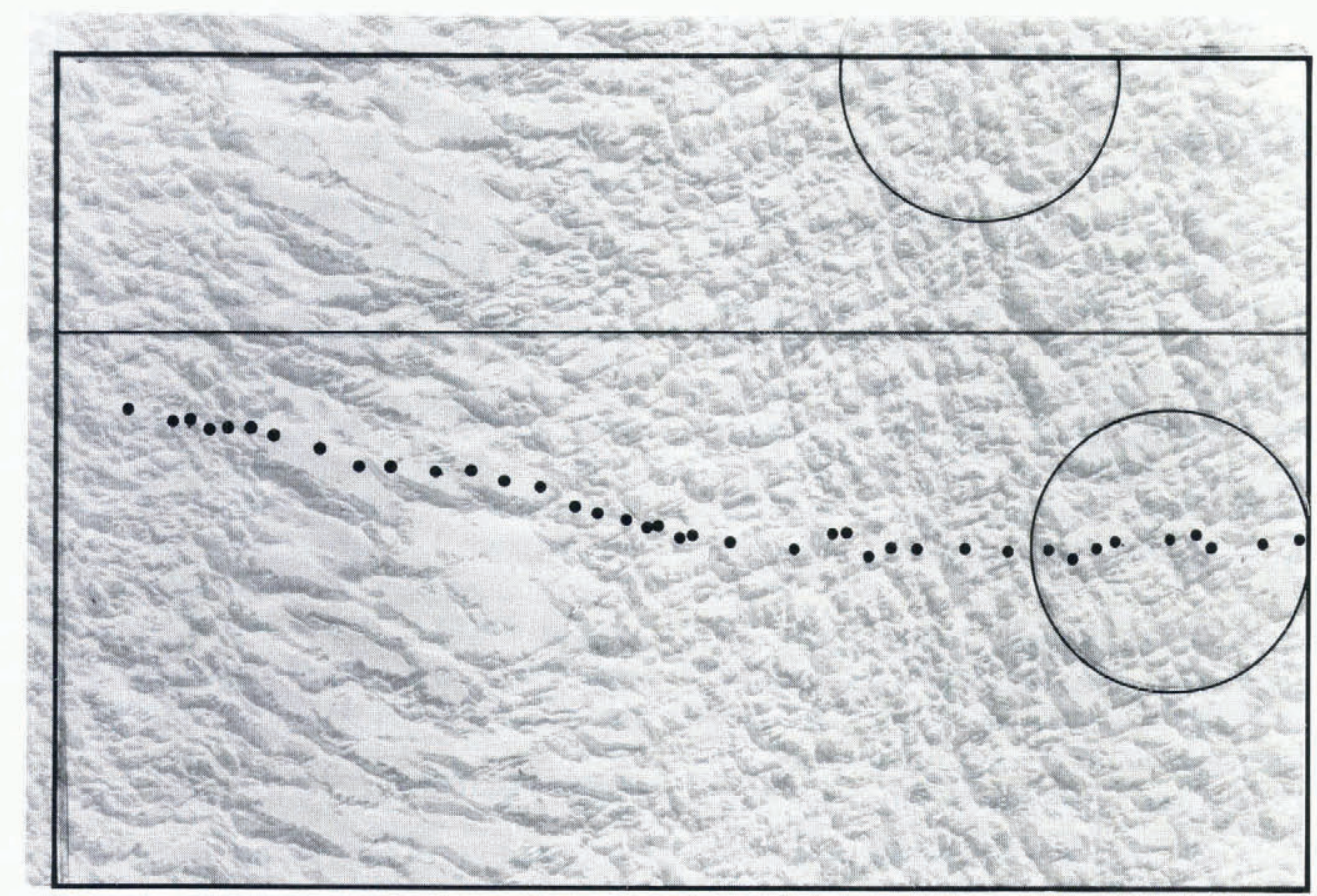

Fig. 4. Aerial photograph showing the points used for measuring velocities (black dots) in the upstream profile. The rectangle corresponds to that shown in Figure 2a. The solid line drawn across the photograph indicates the location of the upstream profile. The large circles are used for indicating the position of control points. 


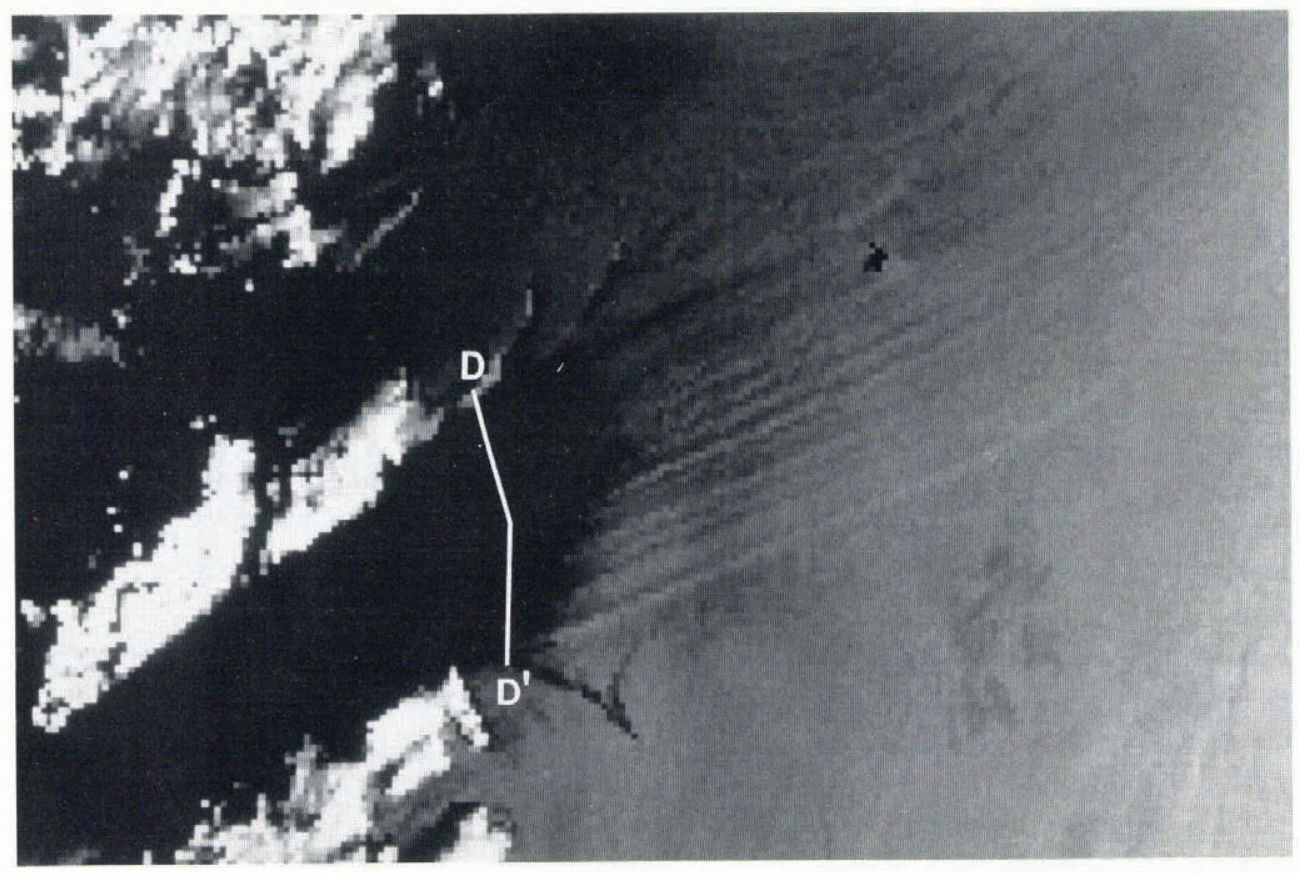

Fig. 6. Near infrared AVHRR image of 2 December 1987, 1659 UTC, showing flow stripes on Byrd Glacier and the Ross Ice Shelf to the right. The profile across Byrd Glacier corresponds approximately to profile DD' on Figure 1 . The image is $127 \mathrm{~km}$ by $194 \mathrm{~km}$.

was computed as $0.01 \mathrm{~m} \mathrm{~d}^{-1}$ based on the measurement precision ( 0.6 to $0.8 \mathrm{~m}$ times $\sqrt{ } 2)$ and the time interval $(56 \mathrm{~d} \pm 3 \mathrm{~h})$. Lateral shear $(\partial v / \partial y)$ is computed based on the longitudinal component of velocity $(v), y$ being the variation occurs at the boundaries of flow stripes. Lateral shear is not significantly different from zero across the profile, and there is no special variation at flow stripe boundaries.

The flow stripes originate $80 \mathrm{~km}$ upstream from the upstream velocity profile (Fig. 1). The present results show that lateral shear is not continuing to create the flow stripes. Some other mechanism such as squeezing of bands of different mechanical properties by lateral compression or a very slow decay rate must account for the stripes.

\section{SATELLITE IMAGERY}

Flow stripes also appear in data from the Advanced Very High Resolution Radiometer (AVHRR) on which they can be traced in the visible (band $1,0.58-0.68 \mu \mathrm{m}$ ), near infrared (band 2, $0.73-1.10 \mu \mathrm{m}$ ) and thermal infrared (band 4, 10.30-11.30 $\mu \mathrm{m}$ and band 5, 11.50-12.50 $\mu \mathrm{m}$ ) bands. The stripes originate on the imagery on glaciers from the Transantarctic Mountains and persist on the Ross Ice Shelf. AVHRR data are used here to assess the decay of flow stripes as they travel across the Ross Ice Shelf.

The AVHRR data have a spatial resolution of $1.1 \mathrm{~km}$ and radiometric resolution of ten bits. The data on visible and near infrared (NIR) bands are very similar, and NIR was selected for analysis. Flow stripes also appear with similar brightness contrast in thermal infrared (TIR) bands. However, in the TIR band regional brightness variations are more complex than in the NIR band. The flow stripes appear in all images that we have investigated, but are enhanced in imagery with sun angle perpendicular to them. Three images with different sun angles were analyzed. They were acquired 2 December 1987, 1659 UTC, and 6 December 1987, 0616 and 1301 UTC.

In Figure 6 flow stripes coming out from Byrd Glacier are seen. Byrd Glacier appears dark in NIR because of low reflectivity of bare ice and the large crevasse density.

Brightness values were inspected across two profiles that coincide closely with the upstream and downstream photogrammetric profiles. Flow stripes are undetectable on the upstream profile on the image because of the small NIR reflectivity on Byrd Glacier. Flow stripes are also undetectable on TIR on the upstream profile due to the warm katabatic wind signature. However, on the downstream profile (DD' on Figure 6) the flow stripes appear on the NIR AVHRR image, each with a width of 1.1$4.4 \mathrm{~km}(1-4$ pixels $)$ and a contrast of 3-10 raw brightness values.

Figure 7 shows flow stripes traced from the AVHRR imagery. Flow stripes disappear downstream from Byrd Glacier, but a few are preserved down to the ice shelf front. Flow stripes decay rapidly on the ice shelf, as can be observed from the AVHRR brightness values. A brightness contrast of 2-6 values associated with flow stripes is observed $40 \mathrm{~km}$ downstream from the downstream profile, which is labelled as location 1 in Figure 7. The brightness contrast of flow stripes decreases to $1-2$ values $140 \mathrm{~km}$ downstream from the downstream profile (location 2 in Figure 7). Most flow stripes disappear downstream from location 2, but a few persist discontinuously to the ice shelf front with a brightness contrast of 1 value.

\section{DISCUSSION}

Comparison of flow stripes from the upstream (UU' on Figure 1) and downstream (DD') photogrammetric profiles shows that flow stripes become wider as they move downstream, but their slopes $(2-7 \%)$ do not change. 


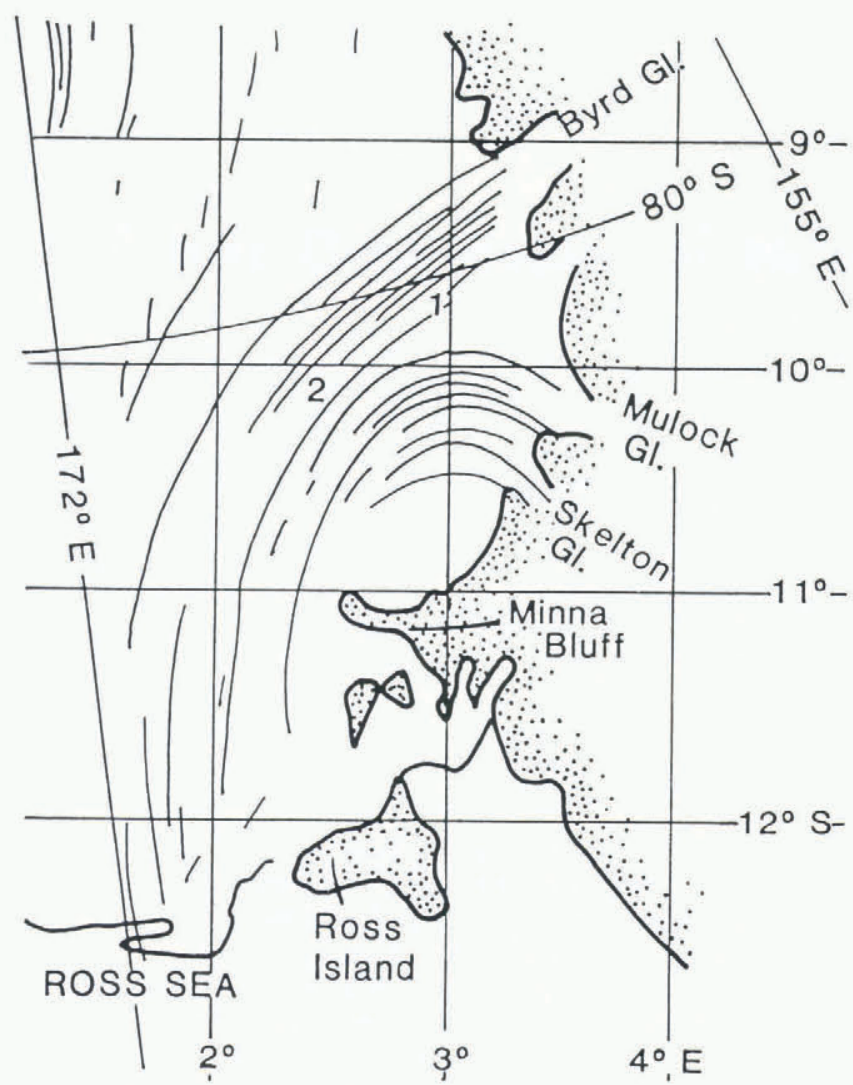

Fig. 7. Flow stripes drawn from AVHRR imagery on the western sector of the Ross Ice Shelf. The grid corresponds to that used by Thomas and others (1984) in which $1^{\circ}$ is equal to $110 \mathrm{~km}$. Flow stripes decay rapidly between Byrd Glacier and location 1. Downstream from location 2 the few flow stripes that persist have a brightness contrast of only 1 AVHRR value.

Inspection of profile $\mathrm{UU}^{\prime}$ shows that flow stripes can be divided in two types. The first corresponds to "textural flow stripes" associated with a distinct crevasse pattern, but not correlated with any surface undulation. The second type are "topographic flow stripes" that correspond both to a surface undulation and also to another distinct crevasse pattern. Vornberger and Whillans (1986) described "crevasse bands" and "longitudinal ridges" on Ice Stream B, which are features similar respectively to our textural and topographic flow stripes.

There is a change from textural to topographic stripes down-glacier. The distinct crevasse pattern which is so prominent in $\mathrm{UU}^{\prime}$ is very subdued in $\mathrm{DD}^{\prime}$, where crevasses are to a large extent covered with snow. Also, narrow flow stripes (less than $1 \mathrm{~km}$ wide) observed in $\mathrm{UU}^{\prime}$ are not present in $\mathrm{DD}^{\prime}$.

Inspection of flow stripes on AVHRR imagery shows that they decay rapidly over the first $40 \mathrm{~km}$ on the ice shelf. This decay is probably the combined effect of removal of surface texture by burial and relaxation of the topography by creep, perhaps enhanced by lateral spreading in this area where Byrd Glacier flows into the Ross Ice Shelf. Thomas and others (1984) do not report strain rate data for this area, but the general geometry of Byrd Glacier suggests positive lateral spreading as it flows into the ice shelf.
As flow stripes are carried downstream from Byrd Glacier, their surface texture is expected to be erased by net accumulation over the ice shelf. This is supported by inspection of Landsat MSS imagery of the margin of the Filchner Ice Shelf (Swithinbank and others, 1988), where no texture is observed associated to flow stripes.

The quantification of the morphology of Byrd Glacier presented here is basic data for understanding the dynamics of flow stripes. Work is now in progress to develop a model for simulating the decay of flow stripes.

\section{ACKNOWLEDGEMENTS}

NASA's Graduate Student Fellowship in Global Change Research supported G.C. The Department of Geodetic Science and Surveying at The Ohio State University provided the use of the analytical stereo plotter. Dr Kenneth Jezek financed the purchase of aerial photographs through a NASA Polar Ocean Program grant, and made suggestions. Dr Ian Whillans made comments on the manuscript. Dr David Bromwich provided the AVHRR images which were obtained from Mr Robert Whritner of the Antarctic Research Center at Scripps Institution of Oceanography. Ms Jane Ferrigno from the United States Geological Survey provided the Landsat image of Figure 1. Mr John C. Nagy of the Byrd Polar Research Center (BPRC) drafted the figures. This is BPRC Contribution No. 818.

\section{REFERENCES}

Brecher, H.H. 1986. Surface velocity determination on large polar glaciers by aerial photogrammetry. Ann. Glaciol., 8, 22-26.

Bromwich, D.H. 1992. A satellite case study of a katabatic surge along the Transantarctic Mountains. Int. F. Remote Sensing, 13(1), 55-66.

Casassa, G., K. C. Jezek, J. Turner and I. M. Whillans. 1991. Relict flow stripes on the Ross Ice Shelf. Ann. Glaciol., 15, 132-138.

Crabtree, R. D. and C. S. M. Doake. 1980. Flow lines on Antarctic ice shelves. Polar Rec., 20(124), 31-37.

Dowdeswell, J. A. and N. F. McIntyre. 1987. The surface topography of large ice masses from Landsat imagery. f. Glaciol., 33(113), 16-23.

Swithinbank, C., K. Brunk and J. Sievers. 1988. A glaciological map of Filchner-Ronne Ice Shelf, Antarctica. Ann. Glaciol., 11, 150-155.

Swithinbank, C. 1988. Satellite image atlas of glaciers of the world: Antarctica. USGS Professional Paper 1386B.

Thomas, R. H., D. R. MacAyeal, D. H. Eilers and D. R. Gaylord. 1984. Glaciological studies on the Ross Ice Shelf, Antarctica, 1973-1978. Antarct. Res. Ser., 42(2), 21-53.

Vornberger, P.L. and I. M. Whillans. 1986. Surface features of Ice Stream B, Marie Byrd Land, West Antarctica. Ann. Glaciol., 8, 168-170.

The accuracy of references in the text and in this list is the responsibility of the authors, to whom queries should be addressed. 